\title{
ROK: a Modulação Cinética tornada fácil
}

Luís Sousa Lobo a

Vários métodos podem ser utilizados para a determinação de constantes cinéticas a partir de dados experimentais. Com frequência se recorre à linearização de expressões cinéticas, fazendo-se então o ajuste pelo método dos mínimos quadrados por simples regressão linear. Devido à existência de erros experimentais, este procedimento é incorrecto. Verifica-se que para erros experimentais superiores a $3 \%$ há desvios na avaliação das constantes que podem ser importantes [ $\left.{ }^{1}\right]$.

O método mais correcto é a regressão não linear. Os algoritmos geralmente utilizados nos programas de computador (do tipo Newton-Raphason ou Newton-Gauss) obrigam contudo a uma estimativa inicial razoável dos parâmetros a avaliar, o que pode não ser fácil, sobretudo em sistemas múltiplos. Estes algoritmos, sendo rápidos, dão portanto problemas de convergência em muitas situações.

Os métodos de optimização de parâmetros em regressão não linear chamados de busca directa não têm sido muito utilizados por serem considerados lentos, embora se reconheça serem robustos. Foi desenvolvido recentemente um programa de computador com o nome de $\mathrm{ROK}\left[{ }^{2}\right]$, que é rápido e robusto. Com este programa, não é em geral preciso fazer estimativas iniciais! A determinação das constantes cinéticas é feita em segundos ou, em casos já complexos, em 1 ou 2 minutos. O utilizador apenas precisa de induzir os dados experimentais e carregar em «RUN». Aparecem no écran do
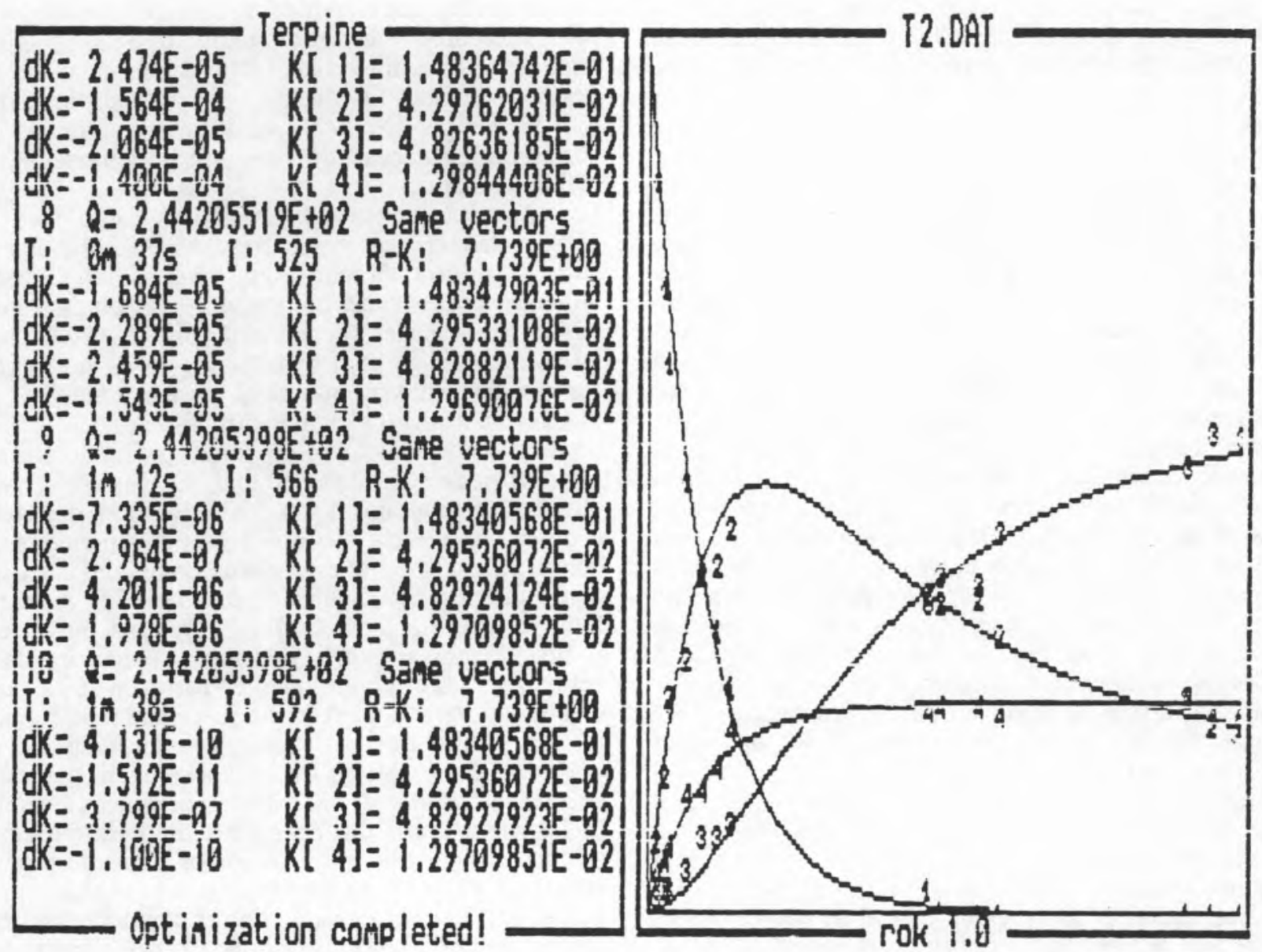

a Departamento de Química, Universidade Nova de Lisboa, 2825 Monte de Caparica. 
monitor os valores das constantes e o ajuste gráfico aos dados experimentais (v. figura). Quando o programa termina o que é avisado por um sinal sonoro, o operador pode simplesmente mandar imprimir o écran. $\mathrm{O}$ algoritmo, escrito em linguagem Pascal para computadores PC, combina integração numérica pelo método Runge-Kutta de $4 .^{\text {a }}$ ordem com um algoritmo de busca directa pelo método das direcções conjugadas (Powell, 1964). São introduzidas várias inovaçס̃es que permitem melhorar a rapidez sem sacrificar a precisão e a robustez.

Este tratamento foi concebido para que o tratamento de dados não pese no trabalho dos cineticistas e não os desvie do seu esforço principal de compreender a cinética e os mecanismos das reaç̧ð̃es químicas. Este objectivo está sendo completamente conseguido pelos investigadores que já utilizam o programa. A produtividade científica e a criatividade, em minha opinião, aumentam apreciavelmente.

O programa ROK pode ser pedido ao autor ou, com a referência QCMP 068, obtido através do Quantum Chemistry Program Exchange, Indiana University, Bloomington, Indiana 47405, EUA [ $\left.{ }^{2}\right]$.

Pode ser feita uma demonstração do programa a pedido (Tel. 01 - 2954464 - ext. 0109).

\section{Referências}

[1] L. Gomes, V. Vital and L.S. Lobo, Paremeter Estimation and Errors in Reaction Kinetics, comunicação a CHEMPOR'89.

[2] L.S. Lobo e M.S. Lobo, ROK - Nonlinear Regression Optimization for Kinetics, QCMP 068, QCPE (1989).

\section{Convite à Reflexão...}

\section{A Ciência do Homem}

É verdade que os especialistas são necessários. A ciência não pode progredir sem eles. Mas a aplicação ao homem do resultado dos seus esforços exige a sintese prévia dos dados dispersos pela análise.

Esta sintese não pode obter-se pela simples reunião de especialistas em volta de uma mesa. Exige o esforço, não de um grupo, mas de um homem. Nunca uma obra de arte foi feita por uma comissão de artistas, nem uma grande descoberta por uma comissão de cientistas. As sinteses de que necessitamos para o progresso do conhecimento de nós próprios devem elaborar-se num único cérebro. Hoje, os dados acumulados pelos especialistas permanecem inutilizáveis. $\mathrm{Na}$ verdade, ninguém coordena as noçōes adquiridas nem considera o ser humano na sua globalidade. Existem muitos trabalhadores científicos mas muito poucos verdadeiros cientistas. Esta singular situação não resulta da ausência de indivíduos capazes de grande esforço intelectual. É verdade que as grandes sínteses exigem muito poder mental e uma resistência física a toda a prova. Os espíritos largos e fortes são mais raros do que os espíritos precisos e estreitos. É fácil ser-se um bom químico, um bom físico, um bom fisiólogo ou um bom psicólogo. Só homens excepcionais são capazes de adquirir um conhecimento útil de várias ciências ao mesmo tempo. Contudo, estes homens existem.

Entre aqueles que as nossas instituiçð̃es científicas e universitárias obrigaram a especializar-se de forma muito estrita, alguns seriam capazes de dominar um grande tema no seu conjunto e nas suas partes. Até agora, têm sido favorecidos os trabalhadores cientificos que se limitam a um campo restrito e se consagram ao estudo prolongado de um pormenor muitas vezes insignificante. Um trabalho original sem importância é considerado possuidor de mais valor do que o conhecimento profundo de toda uma ciência. Os reitores das universidades e os seus conselheiros não compreendem que os espíritos sintéticos são tão indispensáveis como os espíritos analíticos. Se a superioridade deste tipo intelectual fosse reconhecida, e o seu desenvolvimento favorecido, os especialistas deixariam de ser perigosos. Na verdade, o significado das partes na construção do conjunto poderia ser justamente avaliado.

[...] As altas construções sintéticas estão fora do alcance daqueles cujo espírito se dispersa diariamente entre a confusão da maneira de viver actual. O desenvolvimento da ciência do homem, mais ainda do que das outras ciências, depende de um imenso esforço intelectual. Exige uma revisão não só da nossa concepção do cientista, mas também das condições em que se faz a investigação científica.

Só um conhecimento muito mais profundo de nós mesmos pode remediar este mal. Graças a ele, veremos por que mecanismos a existência moderna afecta a nossa consciência e o nosso corpo. Aprenderemos como adaptar-nos a este meio, como defender-nos dele e também como substituí-lo no caso de se tornar indispensável uma revolução. Ao mostrar-nos o que somos, as nossas potencialidades e a maneira de as actualizar, este conhecimento fornecer-nos-á uma explicação para o nosso enfraquecimento fisiológico, para as nossas doenças morais e intelectuais. Só ele nos pode desvendar as leis inexoráveis em que estão encerradas as nossas actividades orgânicas e espirituais, estabelecer a distinção entre o interdito e o permitido, ensinar-nos que não somos livres de modificar, segundo a nossa fantasia, o nosso meio e nós mesmos. $\mathrm{Na}$ verdade, desde que as condiçø̃es naturais da existência foram suprimidas pela civilização moderna, a ciência do homem tornou-se a mais necessária de todas as ciências.

Alexis Carrell, «O Homem, Esse Desconhecido» 